wave; the preparation of a text-book on thermal stresses in nuclear reactors; and several projects related to missiles and satellites, including the design and construction of an advanced type of satellite.

By its Committee of Science and the Arts, its Journal, and by the work of the Biochemical Research Foundation, for which the Institute serves as trustee, the Institute is best known throughout the world. The Medal Day ceremonies organized by the Committee were held on October 21,1959 . The seventeen individual recipients included $\boldsymbol{H}$. A. Bethe, C. $\mathrm{H}$. Townes, and C. M. Zener, and one industrial company. One of the achievements of the Biochemical Research Foundation in its concentrated attack on cancer was the successful isolation of a unique streptomycinindependent strain of $E$. coli which can be used as a screening organism in a search for anti-mutagens. Long-term studies of the effects of nutrition on cancer growth were continued, as well as studies of the metabolic processes of cancer cells. In addition to the Journal the Institute now issues The Institute News eleven times a year, and although intended primarily for Institute members, this four-page newspaper is also distributed to schools, libraries and others interested in science education.

The cosmic ray group of the Bartol Research Foundation of the Institute participated in the
International Geophysical Co-operation, and constructed a new cosmic ray monitor for installation at McMurdo Naval Air Facility in Antaretica, to complement the one in operation at Thule, Greenland. The detector for heavy nuclei contained in the satellite Explorer VII was designed by the Foundation. The Foundation's headquarters are located on the campus of Swarthmore College, and in addition to providing an active programme of scientific colloquia and public lectures, undergraduate students of the College have been encouraged to participate in the Foundation's research programme.

The report concludes by emphasizing that, though the Institute's Laboratories and the Foundation are self-supporting, the accounts indicate that the educational and general activities of the Institute, which must expand to meet the growing need, will soon face a critical financial situation. A total of approximately 204,000 dollars was received in 1959 in gifts, bequests and from other sources, but the net loss for educational and general activities, though reduced from the 1958 figure of 100,000 dollars, was still more than 20,000 dollars, and will rise as the planned expansion gets under way during the next decade. The managers of the Institute appeal to the increased generosity of members and friends of the Institute to provide the necessary additional funds.

\title{
THE ATOMIC ENERGY OF CANADA LIMITED
}

$\mathrm{T}$ HE need for, and the extent of, a nuclear power programme in Canada is one of the main topics of discussion in the annual report of the Atomic Energy of Canada Limited for the year ended March 31 , 1960, which has recently been published*. Although Canada has vast resources of oil, gas, coal and untapped water power, these are not uniformly distributed across the country and already some regions are approaching the point where the conventional power resources will need to be supplemented by nuclear power. The industrial area of southern Ontario is likely to be the first of these regions, and it is fortunate that conditions in this area are favour. able to the early introduction of nuclear power, for not only is the generating capacity of the HydroElectric Power Commission which serves Ontario capable of absorbing the additional 200 or so megawatts, but also there are present in the province of Ontario extensive uranium deposits and large uranium mines.

After considerable examination of the various alternatives and several years experience in the operation of such reactors, it is still the conviction of Atomic Energy of Canada Limited that the type of reactor which is fuelled by natural uranium and moderated by heavy water offers the best promise for early, low-cost nuclear power in large units. The four nuclear power projects which the authority has in hand are described in detail in the report. The first two, the Nuclear Power Demonstration Station being built at Rolphton some twenty miles west of Chalk River, and the Douglas Point plant, are closely related. The reactor at the Nuclear Power Demonstration Station is moderated and cooled by

* Atomic Energy of Canada Limited. Annual Report, 1959-1960. Pp. 36. (Ottawa: Queen's Printer, 1960.) 25 cents. heavy water and uses pressure tubes instead of a pressure shell to contain the coolant. The fuel consists of natural uranium dioxide pellets sheathed in 'Zircaloy' tubes, and the tubes are grouped together in bundles. The Station, which is expected to have an output of $20 \mathrm{MW}$. (electrical) and to go into operation during 1961, is a prototype, and the results of tests carried out at the Station will be used to improve and modify the design of the Douglas Point Station, the construction of which was authorized in June 1959 The clearing of the 2,300-acre site on the eastern shore of Lake Huron began in February 1960, and the Station is scheduled for completion by mid-1964. Provision has been made for two 200-MW. units, but at present only one unit Candu (Canadian deuterium uranium) has been authorized and is under construction.

The third nuclear project, called Ocdre (organic cooled, deuterium moderated, reactor experiment), consists of the development of a nuclear power reactor of medium size which it is hoped will prove attractive to industrial concerns. A preliminary report on the design of such a reactor, which was to be available in August 1960, is to include an estimate of cost of the construction of an experimental reactor. The fourth project is devoted to the study of information relating to small nuclear plants suitable for use in remote regions of Canada.

At the Chalk River Research Establishment both the Nry and Nru reactors were in routine operation during the year, being fully occupied with research experiments, the production of radioisotopes and plutonium, and engineering testing. The several 'Ioops' in the reactors have been used by both the United States Atomic Energy Commission and the United Kingdom Atomic Energy Authority. The 
two small experimental reactors, Zeep and Ptr, were also in constant operation, and a new zero energy, heavy-water moderated reactor, $Z e d-2$, is being constructed and is nearing completion. One of the important lines of fundamental research carried out at Chalk River is the investigation of the structure of the atomic nucleus for which special facilities, such as the experimental reactors and particle accelerators, are provided. During the year under review major ancillary equipment was added to the $10-\mathrm{MeV}$. tandem accelerator for this particular investigation. In the Physics Division a new spectrometer, which employs the neutron beam from the Nru reactor as a probe to examine the forces holding together liquids and solids, was installed. The Research Chemistry Branch was mainly concerned with investigations on the breakdown of molecules exposed to intense radiation and the bombardment of metals with heavy ions. Fuel development, the physical properties of reactor materials, field tests of the method of disposal of fission products by fixing them in glass, and the development of new radiation monitoring instruments, including a tiny radiation detector which uses semiconductors, were some of the applied research problems investigated by the research establishment.

The directors and management of Atomic Energy of Canada Limited gave consideration during the year to the long-range expansion of research and development in the field of atomic energy, and recommended that Chalk River should not continue to expand, but that a new site should be selected at which future expansion could take place. In October 1959, the Government announced the establishment of a new research and development centre in Manitoba, on the east bank of the Winnipeg River between
Seven Sisters and Lac du Bonnet, to be known as the Whiteshell Nuclear Research Establishment. The first major facility to be provided at the new site is likely to be the Ocdre reactor. During October also, Canada and Euratom signed an agreement for co-operation in the peaceful uses of atomic energy and a technical agreement for a joint programme of research and development in heavy-water reactors. A group of Euratom industrialists visited Canada in the autumn to see the various atomic energy facilities. Close co-operation with the United Kingdom Atomic Energy Authority and the United States Atomic Energy Commission continued, as well as with the authorities in Australia, Japan and Pakistan. The number of staff from other countries attached to Atomic Energy of Canada Limited during the year was sixty-two, and was limited only because of lack of working and housing accommodation. The construction of the Canada-India reactor at Trombay, India, is now essentially complete and the initial start-up is scheduled for mid-1960.

The report concludes with the financial accounts of Atomic Energy of Canada Limited and with details of the Commercial Products Division which is responsible for the production, planning, processing and marketing of the radioisotopes produced in the Chalk River reactors. More than half the curies of radioartivity sold by Canada has been for the cobalt therapy machines for the treatment of cancer which were originally developed in Canada. One hundred and eighty-five machines have been installed in thirty countries. Another device recently developed is the Gammacell 220, which is a portable facility for the gamma-irradiation of materials, and fourteen of these units are in service in eight countries.

\section{CONCENTRATION OF PLANKTON PIGMENTS IN AUSTRALIAN WATERS}

$\mathrm{E}$ STIMATIONS of the quantity of plankton pigments are widely used as a measure of the biomass of phytoplankton. They have achieved this popularity through the ease and accuracy of the chemical estimation, and they give results more reliable than most other techniques. However, as G. F. Humphrey emphasizes in a recent paper issued by the Australia:si Commonwealth Scientific and Industrial Research Organization, they have many disadvantages. For example, there is a variable and uncertain relationship between pigments and the chemical composition of the organism, and so they are a poor measure of, say, the cellular carbon. Nevertheless, the pigments are the potential absorbers of the energy used in photosynthesis and the widespread usage of one particular method commends it further (Division of Fisheries and Oceanography. Technical Paper No. 9: The Concentration of Plankton Pigments in Australian Waters. Pp. 27. Melbourne: Commonwealth Scientific and Industrial Research Organization, 1960).

The author, Dr. G. F. Humphrey, who is chief of the Division of Fisheries and Oceanography, has gone to some length in perfecting a satisfactory modification of the Richards and Thompson technique for pigment measurements. He has also ascertained the precision obtained with the method, and for the analyses this amounts to \pm 10 per cent, but the variation between replicate plankton samples is much larger and particularly at greater depths it is shown even to exceed previous estimates of \pm 33 per cent.

The results described were obtained mainly from the Tasman Sea and in particular from two stations at 50 and $100 \mathrm{~m}$. depth off Sydney. The ratios of the pigments varied during the year, with either chlorophyll $a$ or $c$ predominating. Chlorophyll $c$ was frequently in excess and it appeared to be a pigment of major importanee in the deeper waters. It should be mentioned, however, that the units used to express chlorophyll $c$ values cannot be compared in absolute terms with the milligrams of chlorophyll $a$, for the specific absorption coefficient of pure chlorophyll $c$ is not yet known and the determination of the actual weight of chlorophyll $c$ is therefore not possible.

No smooth seasonal variation is evident in the results, but from late winter to late summer there were a series of sharp increases in pigment. There is some evidence that these peaks may be correlated with the prevailing hydrological conditions. The depth distribution suggests that the inorganic 